\title{
Adsorption of Chlorophenol from Aqueous Solution on Fluted and Commercial Activated Carbon
}

\author{
O. A. Ekpete ${ }^{1 *}$, M. Horsfall Jnr ${ }^{2}$ and T. Tarawou ${ }^{2}$ \\ ${ }^{1}$ Dept. of Chemistry, Ignatius Ajuru University of Education, P.M.B 5047 Port Harcourt, \\ Nigeria; ${ }^{2}$ Dept. of Pure \& Industrial Chemistry, University Port Harcourt, Uniport P. O. Box \\ 402, Port Harcourt, Nigeria; e-mail: oekpete@yahoo.com
}

\begin{abstract}
The adsorption of chlorophenol by an agro-based activated carbon prepared from fluted pumpkin stem waste was investigated to assess its possible use as adsorbent. The effect of pH, initial adsorbate concentration, adsorbent dosage and contact time were studied to identify adsorption capacity of the fluted activated carbon (FAC). The results were compared to a commercial activated carbon (CAC). Adsorption data were modelled with the Langmuir, Elovich and Dubinin-Radushkevich classical adsorption isotherms. The data fitted the Elovich isotherm model better than Langmuir and Dubinin-Radushkevich. According to the evaluation using Elovich equation showed the sorption capacity obtained for chlorophenol on fluted activated carbon as $47.62 \mathrm{mg} / \mathrm{g}$ and chlorophenol for commercial activated carbon as 38.46 $\mathrm{mg} / \mathrm{g}$. The data showed that fluted activated carbon derived from fluted pumpkin stem waste, an environmental nuisance in Nigeria could be converted to a useful activated carbon for chlorophenol removal in aqueous solution.
\end{abstract}

Keywords: Chlorophenol, adsorption, fluted pumpkin, aqueous systems, activated carbon.

\section{Introduction}

The presence of heavy metals and organic compounds in the environment can be detrimental to a variety of living species including man. Organic compounds are pollutants of priority concern that enter water bodies through discharge from pharmaceuticals, petrochemical and other chemical manufacturing processes. Chlorophenol represent an important class of environmental water pollutants. ${ }^{1}$ Many of these compounds are present in wastewaters from petrochemical, coal tar, plastic, pesticides and chemical industries, which produce them as chemical intermediates or generate them during chlorination of effluents containing phenol compounds. ${ }^{2,3,4}$ Industrial waste waters are not the only sources of chlorophenol, they could be present in domestic waters since they are widely used as pesticides, disinfectants and antiseptics. In addition, the common water treatment with chlorine could generate chlorophenol since chlorine reacts quite fast with phenols. ${ }^{5}$ The use of activated carbon as a support for removal of organic pollutants is justified by its characteristics high surface area, porous structure, high adsorption capacity and surface chemical nature. The aim of this study was to compare the use

\section{${ }^{*}$ Corresponding author}


of fluted activated carbon (FAC) and commercial activated carbon (CAC) for adsorption of chlorophenol using different adsorption isotherm models.

\section{Experimental Methods}

The test solutions were prepared by diluting a stock solution of chlorophenol to the desired concentrations. A stock solution was obtained by dissolving $1.0 \mathrm{~g}$ of chlorophenol obtained from Merck India in distilled water and diluted to $1000 \mathrm{ml}$. Desired solutions of chlorophenol were prepared with subsequent dilutions of the stock solution. The concentration ranges of chlorophenol prepared from standard solution varied between $40 \mathrm{mgL}^{-1}$ to $100 \mathrm{mgL}^{-1}$. Before mixing the adsorbents, the $\mathrm{pH}$ of each test solution was adjusted to the required value with diluted $0.1 \mathrm{M} \mathrm{H}_{2} \mathrm{SO}_{4}$ and $0.1 \mathrm{M} \mathrm{NaOH}$ solutions. The fluted pumpkins stem waste (Telfairia occidentalis HOOK. F) used for this study was obtained from Iwofe market Rumuolumeni Port Harcourt. The samples were cut into smaller bits washed thoroughly with water, rinsed with distilled water and air-dried. The air-dried fluted pumpkin was carbonized at $350^{\circ} \mathrm{C}$ for two hours and allowed to cool to room temperature for three hours before activation.

A carefully weighed $25.0 \pm 0.01 \mathrm{~g}$ fluted activated carbon (FAC) was placed in a beaker containing $500 \mathrm{~cm}^{3}$ of $0.3 \mathrm{M} \mathrm{H}_{3} \mathrm{PO}_{4}$. The content of the beaker was thoroughly mixed and heated until it formed a paste. The paste was put in a crucible and placed in a furnace which was heated at $300^{\circ} \mathrm{C}$ for thirty minutes. This was allowed to cool, washed with distilled water, oven dried at $105^{\circ} \mathrm{C}$ for four hours to constant weight and ground. It was sieved with a $106 \mu \mathrm{m}$ mesh to obtain a fine powdered activated carbon which was used for the various adsorption experiments. The commercial activated carbon (Sifico Ltd. Surrey England) was bought from a scientific store in Port Harcourt and used without treatment.

\section{Batch adsorption equilibrium}

Equilibrium studies were carried out by contacting $0.2 \mathrm{~g}$ of $\mathrm{FAC}$ and CAC with $100 \mathrm{ml}$ of chlorophenol solution of different initial concentrations $\left(40,50,60,70,80,90,100 \mathrm{mgL}^{-1}\right)$ in $250 \mathrm{ml}$ stopper conical flasks. The samples were agitated on a shaker at $200 \mathrm{rpm}$ constant shaking rate for $1 \mathrm{~h}$. This was immediately centrifuged at $1000 \mathrm{rpm}$ for five minutes and then decanted. The supernatants' were analyzed using a UV/VIS spectrometry at $280 \mathrm{~nm}$ using distilled water as blank. The percent chlorophenol removed by the FAC and CAC were calculated from the difference between the initial $\left(\mathrm{C}_{\mathrm{o}}\right)$ and equilibrium $\left(\mathrm{C}_{\mathrm{e}}\right)$ adsorbate chlorophenol concentrations, which is given in equation (1).

$$
\% R=\frac{C_{o}-C_{e}}{C_{o}} \times 100
$$

\section{Effect of contact time}

The determination of the effect of contact time was carried out by contacting $50 \mathrm{ml}$ chlorophenol solution of $100 \mathrm{mg} \mathrm{L}^{-1}$ into several conical flasks. The optimum amount of $0.2 \mathrm{~g}$ of FAC and CAC were added and covered with cellophane. It was agitated at $200 \mathrm{rpm}$ for the various contact time of 20-120 minutes. This was immediately centrifuged at $1000 \mathrm{rpm}$ for 5 minutes, decanted and analysed. 


\section{Effect of initial concentration}

For the determination of optimum concentration of chlorophenol, solutions of different concentrations of chlorophenol were prepared. $50 \mathrm{ml}$ chlorophenol solutions with concentration range of $40-100 \mathrm{mgL}^{-1}$ were measured into fourteen conical flasks. The $\mathrm{pH}$ of the solutions was adjusted to 5 by adding either $\mathrm{HCl}$ or $\mathrm{NaOH}$ solution. $0.2 \mathrm{~g}$ of the activated carbons were placed in each of the $250 \mathrm{ml}$ conical flask and agitated on a shaker at room temperature $\left(30^{\circ} \mathrm{C}\right)$ for $1 \mathrm{~h}$. This was immediately centrifuged at $1000 \mathrm{rpm}$ for 5 minutes, decanted and analysed.

\section{Effect of $p H$}

The effect of $\mathrm{pH}$ on the amount of chlorophenol removal was analyzed over the $\mathrm{pH}$ range from 2-12. In this study, $50 \mathrm{ml}$ chlorophenol solution of $100 \mathrm{mg} \mathrm{L}^{-1}$ was taken in six stopper conical flask and $0.2 \mathrm{~g}$ of the activated carbons were added and agitated at $200 \mathrm{rpm}$ for $1 \mathrm{~h}$. This was immediately centrifuged at $1000 \mathrm{rpm}$ for 5 minutes, decanted and analyzed.

\section{Effect of temperature}

In this study, $50 \mathrm{ml}$ chlorophenol solution of $100 \mathrm{mgL}^{-1}$ was added into seven $100 \mathrm{ml}$ volumetric flasks. The flasks were labelled $\mathrm{F}_{1}-\mathrm{F}_{7} . \mathrm{O} .2 \mathrm{~g}$ of the $\mathrm{FAC}$ was added to each of the $100 \mathrm{ml}$ volumetric flasks. Flask $\mathrm{F}_{1}$ was placed in a thermostat and set at $30^{\circ} \mathrm{C}$ while flasks $\mathrm{F}_{2}-\mathrm{F}_{7}$ were subjected to varying temperatures of $40,50,60,70,80$ and $90^{\circ} \mathrm{C}$, respectively. It was agitated for $1 \mathrm{~h}$ and immediately centrifuged at $1000 \mathrm{rpm}$ for 5 minutes, decanted and analyzed. The same experiment was carried out using CAC as adsorbent.

\section{Effect of adsorbent dosage}

In order to find out the optimum amount of adsorbent at which maximum adsorption takes place, $50 \mathrm{ml}$ of chlorophenol solution of initial concentration of $100 \mathrm{mgL}^{-1}$ was taken in a series of conical flasks with different quantity of adsorbent $0.2,0.4,0.6,0.8,1.0,1.2$, and $1.4 \mathrm{~g}$ of FAC and CAC. The solution of chlorophenol was agitated for $1 \mathrm{~h}$, filtered through fibre glass filters, centrifuged for 5 minutes decanted and analyzed.

\section{Results and Discussion}

The data for proximate analyses, physical properties of FAC and CAC are presented in Table 1. The proximate analyses showed a low amount of moisture, ash and volatile matter, indicating that the particle density is relatively small and the biomaterial should be an excellent raw material for adsorbents to be used in column or fixed-bed reactors. The porosity and iodine number is comparable to other materials used for batch analysis. ${ }^{6-7}$

\section{Effect of contact time}

The effect of contact time on the percentage removal of chlorophenol from solution on to FAC and CAC was studied. The maximum uptake for chlorophenol is within 60 minutes for FAC and CAC as shown in Fig. 1. In general maximum adsorption was complete for chlorophenol at 60minutes and thereafter the sorption rate was found to decrease. The higher sorption rate at the initial period may be due to an increased number of vacant sites on the adsorbent available at the initial stage. The decrease in the adsorption of chlorophenol with time 
could be due to the accumulation of chlorophenol particles in the vacant sites leading to a decrease in sorption percent at time $70-120$ minutes. ${ }^{8}$

Table 1: Physico-chemical characterization of FAC and CAC

\begin{tabular}{|l|l|l|}
\hline \multicolumn{1}{|c|}{ Property } & FAC & CAC \\
\hline pHpzc & $6.50 \pm 0.02$ & $7.03 \pm 0.01$ \\
\hline Moisture & $19.50 \pm 0.02$ & $16.67 \pm 0.07$ \\
\hline Porosity & $0.89 \pm 0.01$ & $0.77 \pm 0.05$ \\
\hline Iodine & $224.90 \pm 0.50$ & $200.36 \pm 0.30$ \\
\hline Ash\% & $22.38 \pm 0.02$ & $17.1 \pm 0.01$ \\
\hline Volatile & $40.15 \pm 0.06$ & $37.5 \pm 0.03$ \\
\hline Particle density & $3.12 \pm 2.52$ & $3.50 \pm 3.22$ \\
\hline
\end{tabular}

\section{Effect of initial concentration}

The percentage removal of chlorophenol was examined by plotting the percentage of chlorophenol removed against different initial concentrations as shown in Fig. 2. It is observed that the percentage removal of chlorophenol for FAC is higher than on CAC. More than $98 \%$ removal is achieved at all concentration on both activated carbons. Chlorophenol removal for 80 $\mathrm{mg} \mathrm{L}^{-1}$ was $99.65 \%$ on $\mathrm{FAC}$ and $99.00 \%$ on CAC.

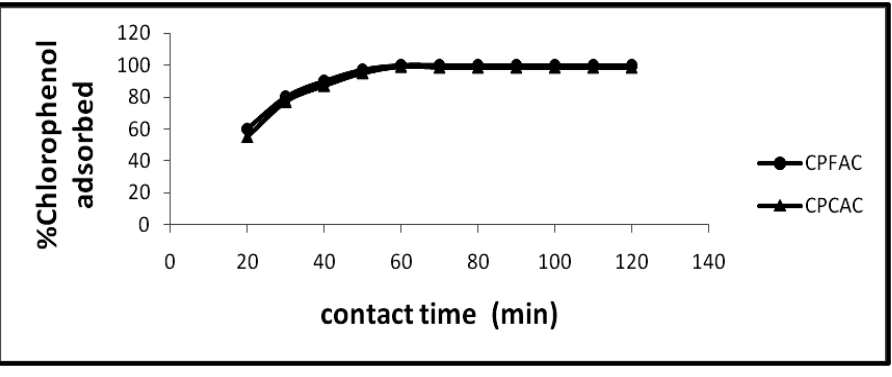

Figure 1: Effect of contact time on the percentage sorption of chlorophenol onto (FAC) and (CAC) (Initial concentration $=100 \mathrm{mg} \mathrm{L}^{-1}, \mathrm{pH}=8$, equilibrium time $=1 \mathrm{hr}$ ). CPFAC means chlorophenol on fluted activated carbon and CPCAC means chlorophenol on commercial activated carbon.

It was also observed that the percentage chlorophenol removal increased with increasing concentrations till $70 \mathrm{mg} \mathrm{L}^{-1}$ for FAC and $80 \mathrm{mg} \mathrm{L}^{-1}$ for CAC, after which a decrease was observed for both adsorbents. ${ }^{9}$ As concentration is increased there is a decrease in percentage removal of chlorophenol due to the accumulation of chlorophenol particles on the surface. ${ }^{10,11}$

\section{Effect of adsorbent dosage}

The effect of adsorbent dosage on chlorophenol removal is shown in Fig. 3. The chlorophenol maximum adsorption obtained with $1.4 \mathrm{~g}$ was $99.95 \%$ on FAC and $99.75 \%$ on CAC. It is evident that for the quantitative removal of different values of chlorophenol a high dosage of fluted and commercial activated carbons are required. The results also clearly indicate that the removal efficiency increases as the dosage increases. 


\section{Effect of $\mathrm{pH}$}

Figure 4 shows that the uptake of chlorophenol by FAC and CAC is increased between $\mathrm{pH}$ 2-8 and decreased thereafter. At $\mathrm{pH} 4$, the carbon surface and the chlorophenolic compound is in a protonated form $\left(\mathrm{pH}<\mathrm{pH}_{\mathrm{pzc}}\right)$ forming better adsorption of chlorophenol. The fact that adsorbed amount decreased with $\mathrm{pH}$ value of 8 can be attributed to the chlorophenol ionization to form chlorophenolate ions. ${ }^{11}$ At low $\mathrm{pH}$ values, the surface of the fluted and commercial

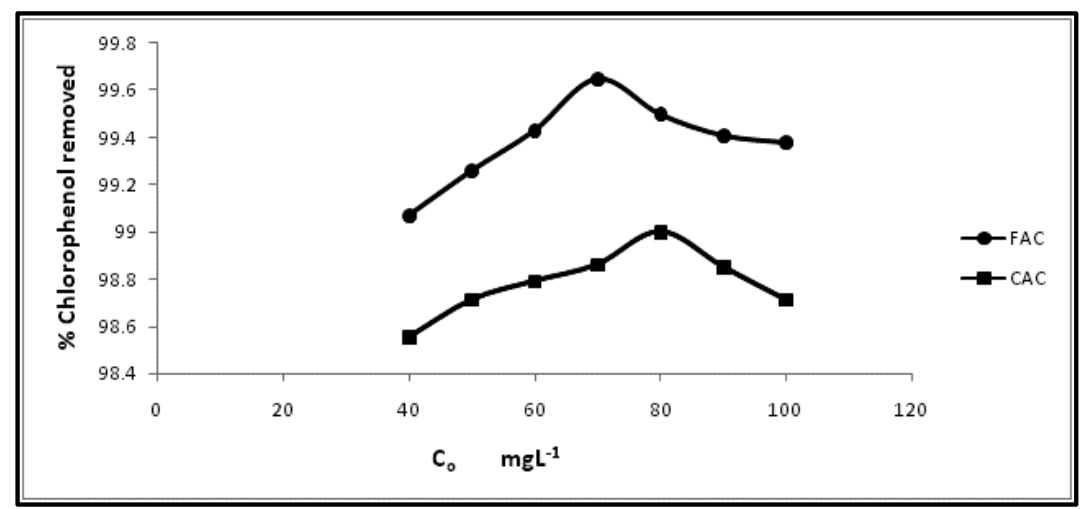

Figure 2: Effect of initial concentration on percentage removal of chlorophenol from solution at $30^{\circ} \mathrm{C}$ from FAC and CAC (initial concentration $=40-100 \mathrm{mgL}^{-1}, p H=8$, equilibrium time $=1 \mathrm{~h}$ ).

activated carbons were protonated which resulted in a stronger attraction for negatively charged chlorophenolate ions. These ions are negatively charged and are directly attracted to the protonated surface of fluted activated carbon by electro-static force. Unionized chlorophenol molecules would also be attracted possibly, by physical force. At high $\mathrm{pH}$, chlorophenol dissociates forming negatively charged chlorophenolate anions, while the surface functional groups are negatively charged.

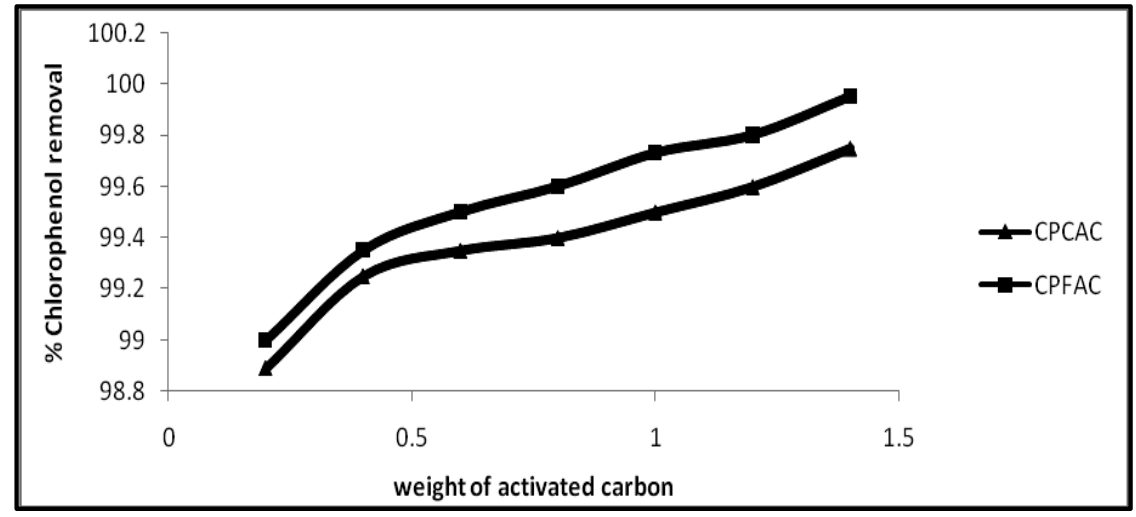

Figure 3: Effect of adsorbent dosage on the adsorption of chlorophenol on to FAC and CAC (initial concentration $=100 \mathrm{mgL}^{-1}, \mathrm{pH}=8$, equilibrium time $=1 \mathrm{~h}$ ) 


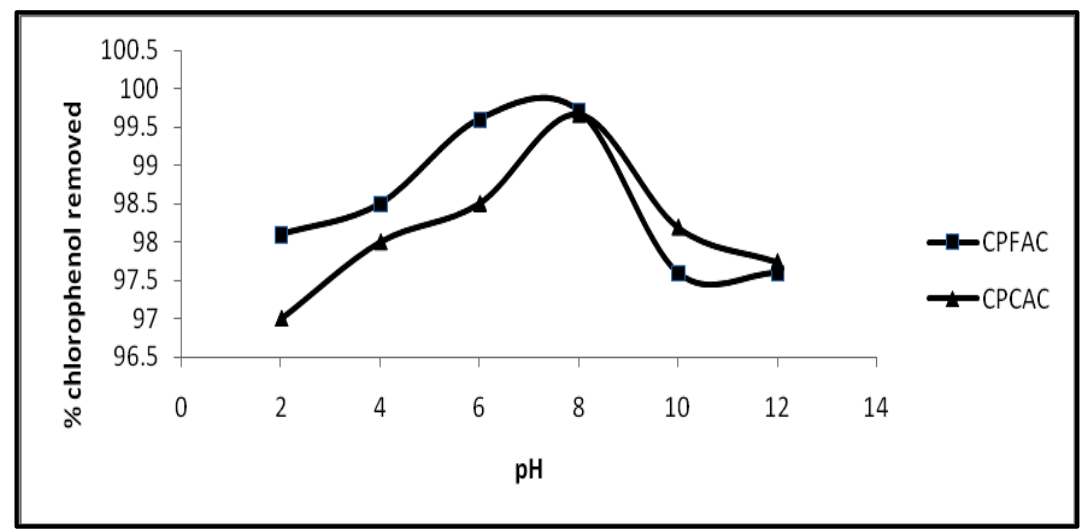

Figure 4: Effect of $\mathrm{pH}$ on the percentage removal of chlorophenol from solution onto FAC and $C A C$ (initial concentration $=100 \mathrm{mgL}^{-1}, p H=8$, equilibrium time $=1 \mathrm{~h}$ )

\section{Effect of temperature}

The relatively slight decrease in the percentage of chlorophenol removed with increase in temperatures may be due to the tendency of the chlorophenol to escape from the solid phase of activated carbon to the liquid phase with an increase in temperature of the solution. This is in agreement with the fact that as temperature increases, the quantity of materials adsorbed decreases and as a result, the percentage of chlorophenol removed at higher temperatures is less than the percentage of chlorophenol removed at lower temperatures as shown in Fig. 5. The overall high percentage of chlorophenol removal from solution could possibly be due to adsorption through ion exchange, hydrogen bonding, van-der Waal's forces as well as intraparticle diffusion. The rapid removal of chlorophenol further indicates that both physisorption and chemisorptions processes may be involved in the adsorption of the chlorophenol by the fluted and the commercial activated carbon. These observations have been made by workers using Tendu leaf biomass ${ }^{12}$ and water hyacinth biomass. ${ }^{13}$

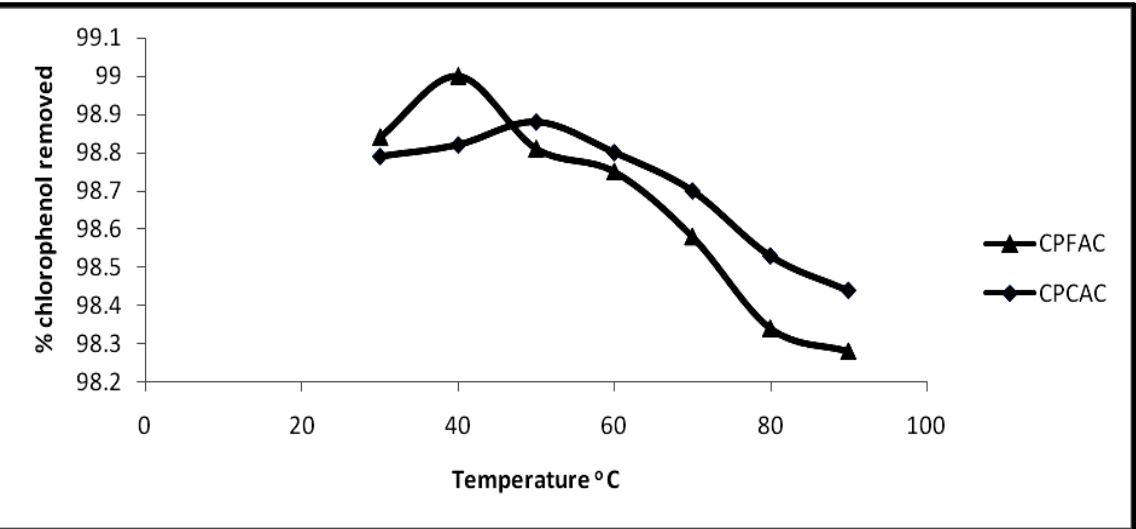

Figure 5: Effect of temperature on the percentage removal of chlorophenol from solution onto $F A C$ and $C A C$ (initial concentration $=100 \mathrm{mgL}^{-1}, p H=8$, equilibrium time $=1 \mathrm{~h}$ ) 


\section{Adsorption isotherms}

The Langmuir isotherm model was chosen for the estimation of maximum adsorption capacity corresponding to complete monolayer coverage on the activated carbon surface.

The Langmuir equation is expressed as

$$
q_{e}=\frac{q_{m} k_{L} c_{e}}{1+k_{L} c_{e}}
$$

on linearlizing, equation (2) becomes

$$
\frac{C_{e}}{q_{e}}=\frac{1}{q_{m} k_{L}}+\frac{c_{e}}{q_{m}}
$$

The plots of specific sorption $\left(\mathrm{C}_{\mathrm{e}} / \mathrm{q}_{\mathrm{e}}\right)$ against $\mathrm{C}_{\mathrm{e}}$ are shown in Fig. 6 and the linear isotherm parameters $\mathrm{q}_{\mathrm{m}}, \mathrm{K}_{\mathrm{L}}$ and the coefficient of determinations are presented in Table 2. The sorption capacity, $\mathrm{q}_{\mathrm{m}}$ which is a measure of the maximum sorption capacity corresponding to complete monolayer coverage showed that the maximum adsorption capacity of chlorophenol and regression are better on CAC (35.71 mgg $\mathrm{mg}^{-1}$ and 0.992) than on FAC (26.31 mgg ${ }^{-1}$ and 0.996 regression).

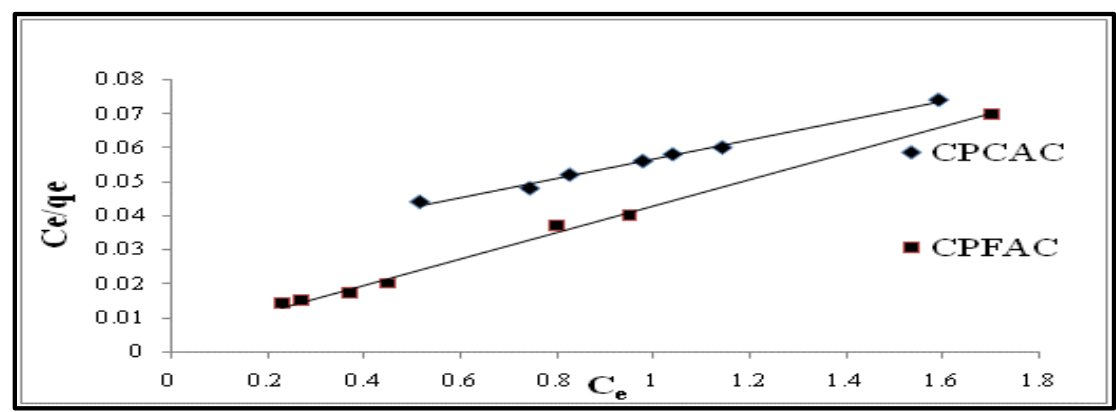

Figure 6: Langmuir plot for chlorophenol from aqueous solution by FAC and CAC

The adsorption coefficient $\left(\mathrm{K}_{\mathrm{L}}\right)$ that is related to the apparent energy of sorption for chlorophenol on FAC is $\left(12.669 \mathrm{dm}^{3} \mathrm{~g}^{-1}\right)$ and chlorophenol on CAC is $\left(1.0 \mathrm{dm}^{3} \mathrm{~g}^{-1}\right)$. The adsorption data for chlorophenol onto activated carbons were analyzed by a regression analysis of Langmuir isotherm model. The favourable nature of adsorption was expressed in terms of a dimensionless equilibrium parameters $\mathrm{R}_{\mathrm{L}}=1 /\left(1+\mathrm{K}_{\mathrm{L}} \mathrm{C}_{\mathrm{O}}\right) .{ }^{14}$ Where $\mathrm{K}_{\mathrm{L}}$ is the Langmuir constant and $\mathrm{C}_{\mathrm{o}}$ is the initial concentration of the adsorbate in solution. The values of $\mathrm{R}_{\mathrm{L}}$ indicates the type of isotherm to be irreversible $\left(R_{L}=0\right)$, favourable $\left(0<R_{L}<1\right)$, linear $\left(R_{L}=1\right)$ or unfavourable $\left(\mathrm{R}_{\mathrm{L}}>1\right)$. The dimensionless separation factors calculated for, 2-CPFAC, and 2-CPCAC were 0.015 and 0.019 . $\mathrm{R}_{\mathrm{L}}$ values were less than one indicating favourable adsorption.

Table 2: Equilibrium constants obtained from Langmuir isotherm

\begin{tabular}{|l|l|l|l|l|l|}
\hline Adsorbate & Adsorbent & $\mathrm{q}_{\mathrm{m}}\left(\mathrm{mgg}^{-1}\right)$ & $\mathrm{K}_{\mathrm{L}} \mathrm{dm}^{3} \mathrm{~g}^{-1}$ & $\mathrm{R}^{2}$ & $\mathrm{~S}_{\mathrm{F}}$ \\
\hline Chlorophenol & FAC & 26.31 & 12.669 & 0.996 & 0.015 \\
\hline Chlorophenol & CAC & 35.71 & 1.000 & 0.992 & 0.019 \\
\hline
\end{tabular}


The Elovich isotherm model was used also chosen for estimation of $\mathrm{K}_{\mathrm{E}}$ and $\mathrm{q}_{\mathrm{m}}$ as well as the coefficients of correlation, $R^{2}$. The linear form of Elovich isotherm, equation (4), is given below;

$$
\left.\frac{q_{e}}{q_{m}}=k_{E} C_{e}^{e x p}-\frac{q_{e}}{q_{m}}\right)
$$

where, $\mathrm{K}_{\mathrm{E}}$ is the Elovich equilibrium constant and $\mathrm{q}_{\mathrm{m}}$ is the Elovich maximum adsorption capacity. If the adsorption obeys Elovich equation, Elovich maximum adsorption capacity and Elovich constant were calculated from the slopes and the intercepts of the plot $\ln \left(\mathrm{q}_{\mathrm{e}} / \mathrm{c}_{\mathrm{e}}\right)$ versus $\mathrm{q}_{\mathrm{e}}$ as shown in Fig. 7. Equilibrium constant obtained from the Elovich isotherm plot are tabulated in Table 3.

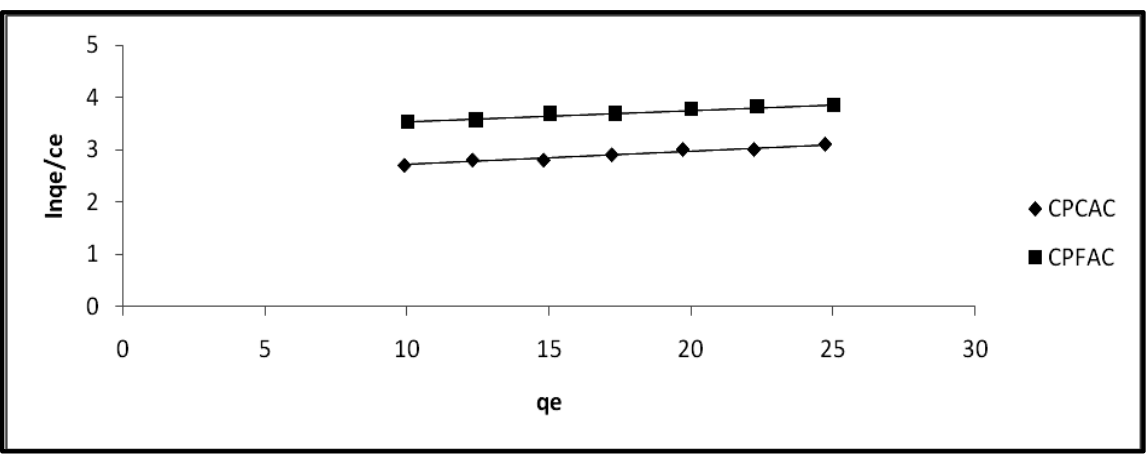

Figure 7: Elovich equibrium isotherm model for the sorption of chlorophenol onto FAC and $C A C$

Table 3: Equilibrium constants obtained from Elovich isotherm

\begin{tabular}{|l|l|l|l|l|}
\hline Adsorbate & Adsorbent & $\mathrm{K}_{\mathrm{E}}$ & $\mathrm{q}_{\mathrm{m}}\left(\mathrm{mgg}^{-1}\right)$ & $\mathrm{R}^{2}$ \\
\hline Chlorophenol & FAC & 1.052 & 47.62 & 0.955 \\
\hline Chlorophenol & CAC & 1.066 & 38.46 & 0.963 \\
\hline
\end{tabular}

Futheremore, Dubinin-Raduskevichisotherm model was used to study adsorption. The linear form of the Dubinin-Radushkevich is represented by equation (5) as given below;

$$
\ln q_{e}=\ln q_{m}-\beta_{\epsilon}{ }^{2}
$$

where, $\beta$ is related to the free energy of sorption and $\mathrm{q}_{\mathrm{m}}$ is the Dubinin-Radushkevich isotherm constants related to the degree of sorbate sorption by the activated carbon surface. $\varepsilon$ is known as Polanyi potential and it is expressed by equation (6) as follows;

$$
\varepsilon=\mathrm{R} \mathrm{T} \ln \left(1+\frac{1}{c_{e}}\right)
$$

where, $\mathrm{C}_{\mathrm{e}}$ is equilibrium concentration of solute and $\mathrm{R}$ the gas constant $\left(\mathrm{Jmol}^{-1} \mathrm{~K}^{-1}\right)$ and $\mathrm{T}$ is the absolute temperature. A plot of $l n q_{e}$ against $\varepsilon^{2}$ yielding a straight line was made to confirm the model. The mean free energy of adsorption $\left(E_{a}\right)$ from the Dubinin-Radushkevich equation was 
computed using equation (7) as follows ${ }^{15}$;

$$
E_{a}=(-2 \beta)^{-1 / 2}
$$

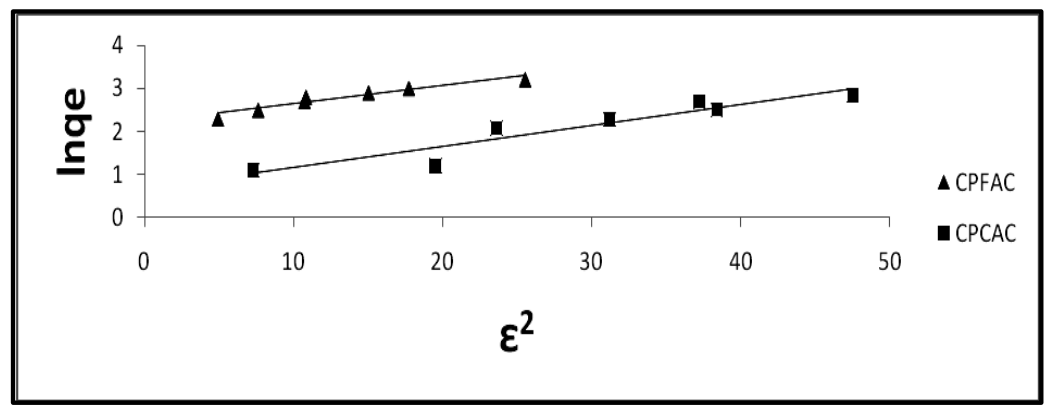

Figure 8: Dubinin-Rasdushkevich equibrium isotherm model for the sorption of chlorophenol onto FAC and CAC.

The sorption affinity of the activated carbon for chlorophenol FAC and CAC are 9.180 $\mathrm{mg} . \mathrm{g}^{-1}$ and $1.968 \mathrm{mg} \cdot \mathrm{g}^{-1}$ respectively indicating that the fluted activated carbon had a greater affinity for chlorophenol. The values of maximum adsorption capacity determined using the linear transformation of the Elovich equation (Table 3) is much higher than the DubininRadushkevich (Table 4). The values of maximum adsorption capacity determined using the linear transformation of the Elovich equation for CPFAC is $47.62 \mathrm{mgg}^{-1}$ and is higher than the value for CPFAC $9.180 \mathrm{mgg}^{-1}$. The correlation coefficient value $\left(\mathrm{R}^{2}\right)$ for CPFAC is 0.955 and for CPFAC is 0.916 for Dubinin-Radushkevich. The higher regression value of 0.963 for CPCAC and 0. 955 for CPFAC for Elovich isotherm may be able to describe the adsorption of chlorophenol onto commercial activated carbon better than fluted activated carbon.

Table 4: Equilibrium constants obtained from Dubinin-Radushkevich isotherm

\begin{tabular}{|l|c|c|c|c|c|}
\hline \multicolumn{1}{|c|}{ Adsorbate } & Adsorbent & $\mathrm{q}_{\mathrm{m}} / \mathrm{mg} \cdot \mathrm{g}^{-1}$ & $\beta / \mathrm{mol}^{2} \mathrm{~J}^{2}$ & $\mathrm{E}_{\mathrm{a}} / \mathrm{KJmol}^{-1}$ & $\mathrm{R}^{2}$ \\
\hline Chlorophenol & FAC & 9.180 & 0.021 & -0.205 & 0.916 \\
\hline Chlorophenol & CAC & 1.968 & 0.024 & -0.219 & 0889 \\
\hline
\end{tabular}

The porosity actor $\beta$ for the activated carbon towards chlorophenol using DubininRadushkevich isotherm was CPFAC 0.021 and CPCAC 0.024 . The porosity factors were found to be less than unity indicating that sorption of chlorophenol may be significant in an industrial effluent. ${ }^{15}$ The apparent free energies from the Dubinin-Radushkevich model for the sorption process are $-0.205 \mathrm{KJmol}^{-1}$ (CPFAC) and $-0.219 \mathrm{KJmol}^{-1}$, respectively. The negative values of $\mathrm{E}_{\mathrm{a}}$ indicate the sorption process is exothermic and that the lower solution temperature will favor the sorption process ${ }^{15}$.

\section{Conclusions}

The following conclusions are drawn from the experimental results of this study: 
1. Adsorbent prepared from fluted pumpkin compared favorably to commercial activated carbon for the removal of chlorophenol from aqueous solution.

2. Adsorption process of chlorophenol from aqueous solution favored Elovich than Langmuir and Dubinin -Radushkevich isotherm model

3. Adsorption of chlorophenol showed the sorption capacity obtained for chlorophenol on fluted activated carbon as $47.62 \mathrm{mg} \cdot \mathrm{g}^{-1}$ and for commercial activated carbon as 38.46 mg. $\mathrm{g}^{-1}$.

4. Removal of chlorophenol increases with increase of adsorbent dosage.

5. The maximum adsorption of chlorophenol was at $\mathrm{pH} 8$ for both activated carbons.

\section{References}

1. A.Denzeli, N. Cihangir, A.Y Rad, Taner M and G. Alsancak, Process. Biochem., 2004.37, 2025.

2. U.S.Environmental Protection Agency (1987). Health and Environmental Effects Profile for Phenol. EPA/600/x-87/121-Enviromental Criteria and Assessment and Development Cincinnati, $\mathrm{OH}$.

3. E. Leyva, I. Crispin, E. Motoctezuma, and S.Leyva, Arkivoc., 2003, 11, 203

4. G.Prpich and A. Daugulis, Biodegradation., 2005, 16, 329

5. A. Denzeli, N.Cihangir, N. Tuzmen and G. Alsancak, Bio resource. Technol., 2005, 6, 59

6. T. Tarawou, M. Horsfall, Jnr and J.L.Vicente, Chemistry \& Biodiversity., 2007, 4, 2236

7. M. Horsfall, A. Abia and A. I. Spiff, African. J. Biotechnol., 2003, 2, 969

8. VA.Vadivelan and KV. Kumar, J. Colloid interface Sci., 2005, 286, 90

9. Q.Hamdaoui and E.Naffrechoux, J. Hazardous. Materials, 2007, 147, 381

10. M.Uddin, M. Islam and M. Abedin, ARPN. J. Eng. Appl. Sci., 2007, 2, 11

11. A.Mahvi, A. Maleki and A. Eslami, American. J. Appl .Sci., 2004, 4, 321.

12. F. Banat, A.Al-Bashir, B.Al-Asheh and O.Hayajneh, Environmental. Pollution., 2000,107, 391

13. G.Nagda, M. Diwan, S. Ghole, Applied. Ecology. Environmental. Research., 2007,5, 1

14. M. Horsfall Jnr and A.I. Spiff, Acta. Chim. Slov., 2004, 18, 85

15. M. Horsfall, Jnr and A.I. Spiff, African. J. Biotechnol., 2005, 4, 191 